\title{
THE RISK FOR THE FEMALE ATHLETE TRIAD IN BRAZILIAN ATHLETES
}

original paper

(c) University School of Physical Education in Wroclaw

DOI: https://doi.org/10.5114/hm.2021.100013

\section{UYARA PEREIRA DE MARIA, CLAUDIA RIDEL JUZWIAK}

Federal University of São Paulo, São Paulo, Brazil

\begin{abstract}
Purpose. The female athlete triad (triad) is a medical condition observed in athletes and physically active females. Its components are low energy availability, with or without an eating disorder, amenorrhea, and osteoporosis. The aims of this study were to identify the triad risk in Brazilian athletes and to characterize the prevalence of symptoms associated with the triad risk.
\end{abstract}

Methods. CrossFit, endurance, aesthetic, combat, and team sports female athletes aged 18-39 years, training $\geq 5$ hours/week and regularly competing answered the Brazilian version of the Low Energy Availability in Females Questionnaire (LEAF-Q). Results. Triad risk, corresponding to a LEAF-Q score $\geq 8$, was identified in $34 \%$ of the participants. Combat athletes presented the highest mean LEAF-Q score [10.6 (3.0); $p<0.05$ ] and injury score [4.8 (1.6); $p<0.05]$. Overall, 48 athletes reported an injury due to training overload in the previous year; this type of injury was associated with the triad risk $(p<0.05)$. A LEAF-Q score $\geq 8$ was related to gastrointestinal $(p<0.05)$ and menstrual dysfunctions $(p<0.001)$. A high prevalence $(46.4 \%)$ of self-reported menstrual dysfunction was observed. A higher percentage (50\%) of weight-sensitive sports athletes than of team sports athletes presented LEAF-Q score $\geq 8$.

Conclusions. Triad risk was observed in Brazilian athletes competing in numerous sports; however, weight-sensitive sports athletes, especially combat athletes, are more vulnerable to the triad risk. LEAF-Q is a reliable tool to identify athletes at risk of developing the triad and symptoms related to low energy availability.

Key words: nutrition, health, nutritional and metabolic diseases

\section{Introduction}

In 2007, the American College of Sports Medicine described the female athlete triad (triad) as a syndrome that associated 3 components: low energy availability (LEA), with or without an eating disorder, amenorrhea, and osteoporosis [1].

Energy availability is the difference between the energy intake and the exercise energy expenditure adjusted to the fat-free mass [2]. LEA represents a mismatch between an athlete's energy intake and the energy expended during exercise, leading to an inadequate remaining amount of energy to support normal metabolic processes required by the body to maintain optimal health and performance [3]. Disordered eating is the most common component in LEA cases and typically occurs among weight-sensitive sports athletes [4]. However, LEA may happen without this psychological component, when athletes intentionally follow extreme methods to reduce body mass or body fat or when they are unaware of their high exercise energy expenditure and remain unable to consume enough food to compensate it [5].

There are several methods to estimate energy intake, exercise energy expenditure, and fat-free mass in athletes, and there is no standardized protocol for undertaking them [3]. Energy intake can be assessed by using 3-7-day dietary logs, 24-hour food recall, or a food-frequency questionnaire [6]; however, food records are subjected to errors of underreporting and do not reflect long-term usual intake [5]. To objectively measure exercise energy expenditure, GPS units, heart rate monitors, power meters, and doubly labelled water, the gold standard, are used, but besides their being costly and challenging to apply in free-living athletes $[5,7]$, there is no consensus on which activities con-

Correspondence address: Uyara Pereira De Maria, Federal University of São Paulo, Rua Silva Jardim, 136 - Vila Matias

- Santos/SP, Brazil - 11015-020, e-mail: uyaramaria@uol.com.br

Received: September 19, 2019

Accepted for publication: February 4, 2020

Citation: De Maria UP, Juzwiak CR. The risk for the female athlete triad in Brazilian athletes. Hum Mov. 2021;22(2):53-59; doi: https://doi.org/10.5114/hm.2021.100013. 
U. De Maria, C. Juzwiak, The risk for the female athlete triad in Brazilian athletes

stitute the exercise to be evaluated [5]. Dual-energy $\mathrm{X}$-ray absorptiometry provides a reasonably precise measure of fat-free mass, yet it is also costly, requires specialist training and equipment, and investigators have to be aware of factors such as hydration status or recent exercise or food/drink intake [5, 8], which can influence results. In summary, the estimation of energy availability is difficult, time-intensive, expensive, bothersome for athletes, and dependent on the subject's commitment and compliance; it also requires resources and professional expertise [5, 7].

Given the difficulty in measuring energy availability components and in identifying LEA, Melin et al. [9] developed and validated the Low Energy Availability in Females Questionnaire (LEAF-Q), whose purpose is to identify female athletes at risk for the triad, with the consideration of LEA as its main component.

The triad prevalence in the Brazilian population is poorly studied. A literature review on the triad prevalence in Brazilian athletes yielded 4 studies, and LEA was considered as the triad main component in only 1 study, conducted among tennis players [10]. On the other hand, 3 studies indicated an eating disorder and/ or disordered eating as triad main component [11-13]. The prevalence of the triad in these studies varied from $1.3 \%$ to $4.2 \%$ [10-13].

Given the importance of knowing more about the triad, in its current definition, in the Brazilian setting, the aims of the present study were: (1) to identify the risk for the triad in Brazilian athletes of several sports disciplines using the Brazilian version of LEAF-Q [14]; (2) to characterize and compare the prevalence of factors associated with the risk for the triad by using an international criterion [9]; and (3) to compare the risk for the triad among Brazilian athletes of several sports disciplines.

\section{Material and methods}

\section{Participants}

A total of 160 Brazilian female athletes, from 4 cities (São Paulo, Campinas, Santos, and Curitiba), engaged in several sports disciplines, were contacted. They were eligible for inclusion if they were women between 18 and 39 years of age who trained $\geq 5$ hours/week and were regularly competing. The exclusion criteria were pregnancy, chronic illnesses, the use of hormonal contraceptives, and the presence of injuries at the time of the questionnaire application that prevented them from training for $\geq 2$ weeks. The inclusion and exclusion criteria adopted were the same as those used by Melin et al. [9] in the original LEAF-Q development and validation process.

A total of 33 athletes reported using hormonal contraception methods and therefore they were excluded. The final sample that completed the study included 127 athletes of several sports disciplines: CrossFit, endurance (running, triathlon, swimming, and cycling), aesthetic (rhythmic gymnastics), combat (Muay Thai, jiu-jitsu, and mixed martial arts), and team sports (basketball, volleyball, handball, soccer, indoor soccer, and rugby).

Low Energy Availability in Females

Questionnaire (LEAF-Q)

LEAF-Q is a self-reported screening tool developed and validated among endurance athletes and dancers of English, Swedish, and Danish origin, used to identify female athletes at risk for the triad [9]. The questionnaire includes 25 items on previous year injury history, as well as the gastrointestinal and menstrual function, which are physiological symptoms related to LEA [9]. Participants who score $\geq 8$ in LEAF-Q are considered at risk for the triad [9]. Furthermore, each LEAF-Q domain presents a cut-off point indicating dysfunction: $\geq 2$ for injury history, $\geq 2$ for gastrointestinal function, and $\geq 4$ for menstrual function [9].

The Brazilian version of LEAF-Q was translated, culturally adapted, and validated among 127 Brazilian female athletes of several sports disciplines [14]. After a complete translation, adaptation, and content validity process with the contribution of a sports experts panel with triad knowledge, the Brazilian LEAF-Q maintained the original format and number of questions, without any addition, removal, or rearrangement of items $[15,16]$. The final version had an adequate performance in the test-retest reliability, presenting an excellent intraclass correlation coefficient of 0.92, which was reinforced by the Bland-Altman plot and McNemar's test and paired $t$-test that demonstrated $p \geq 0.05$, revealing no difference in the LEAF-Q score or risk for the triad diagnosis between test and retest [14]. The Brazilian version also showed validation evidence, by construct validity analysis using the knowngroups method, which corroborated that athletes who compete in weight-sensitive sports presented higher LEAF-Q scores than team sports athletes $(p \leq 0.05)$, to identify Brazilian female athletes at risk for the triad [14]. The international cut-off point based on the Anglo-Saxon population proposed by Melin et al. [9] was adopted in this first study in which the Brazilian version of LEAF-Q was applied. 
In this study, the participants completed a paper version of the Brazilian version of LEAF-Q [14].

\section{Statistical analysis}

Data were processed with the IBM SPSS statistical software version 22.0 for Windows (New York, USA). Descriptive, anthropometric, and demographic data are presented as means and standard deviations. For categorical data, results were expressed as absolute numbers $(n)$ and percentages (\%). Chi-square analysis was used to compare categorical variables and to explore associations between the triad risk and variables of interest, such as sports discipline and the LEAF-Q constructs or domains. One-way analysis of variance was applied for the comparison of the scores among athletes of different sports disciplines, with the Bonferroni method for post-hoc correction. Significance was set a priori at $p<0.05$.

\section{Ethical approval}

The research related to human use has complied with all the relevant national regulations and institutional policies, has followed the tenets of the Declaration of Helsinki, and has been approved by the Research Ethics Committee of the Federal University of São Paulo (reference number: 2.044.177).

\section{Informed consent}

Written informed consent has been obtained from all individuals included in this study.

\section{Results}

The athletes' anthropometric characteristics, training loads, and LEAF-Q scores are shown in Table 1. The risk for the triad, with a LEAF-Q score $\geq 8$, was identified in $33.8 \%$ of the 127 participants who answered the Brazilian version of the questionnaire.

The risk for the triad, or LEAF-Q $\geq 8$, was associated $(p \leq 0.05)$ with each LEAF-Q domain score (injury, gastrointestinal symptoms, and menstrual dysfunction). Table 1 summarizes the mean scores presented by athletes in each sports discipline. Overall, 63 participants (49.6\%) reported the absence of training and/ or competition due to the occurrence of injury in the previous year and 48 athletes (37.8\%) experienced training overload injuries in the same period. The occurrence of this type of injury was statistically significantly associated with the risk for the triad $(p=0.02)$.

The results showed a relationship ( $p=0.001)$ between combat sports and the risk for the triad, as $84.6 \%$ of combat athletes scored $\geq 8$ in LEAF-Q. On the other hand, there was no association between the risk for the triad and team sports or CrossFit. No association between the triad risk and body mass, body mass index, or weekly hours of exercise was found in this study.

A total of 29 athletes $(22.8 \%)$ scored $\geq 4$ in the menstrual function domain; 11 participants $(8.7 \%)$ self-reported menstrual cycles longer than 45 days, $25.9 \%$ indicated absence of menstruation for at least 3 consecutive months, and $11.8 \%$ have had menarche

Table 1. Characteristics and LEAF-Q scores of Brazilian female athletes $(n=127)$

\begin{tabular}{lcccrr}
\hline Characteristics & $\begin{array}{c}\text { Endurance sports } \\
(n=22)\end{array}$ & $\begin{array}{c}\text { Aesthetic sports } \\
(n=3)\end{array}$ & $\begin{array}{c}\text { Combat sports } \\
(n=13)\end{array}$ & $\begin{array}{c}\text { Team sports } \\
(n=57)\end{array}$ & $\begin{array}{c}\text { CrossFit } \\
(n=32)\end{array}$ \\
\hline Age (years) & $32.8(5.3)$ & $18.3(0.6)^{\mathrm{a}}$ & $28.1(5.4)$ & $23.5(4.6)^{\mathrm{b}}$ & $29.8(6.0)$ \\
Height $(\mathrm{cm})$ & $163.3(5.8)$ & $164(1.7)$ & $168.1(8.1)$ & $167(7.5)$ & $164.4(7.7)$ \\
Body mass $(\mathrm{kg})$ & $60.9(6.5)$ & $53(1.0)^{\mathrm{c}}$ & $68.8(11.3)$ & $64.4(9.1)$ & $65.7(8.5)$ \\
BMI $\left(\mathrm{kg} / \mathrm{m}^{2}\right)$ & $22.9(2.6)$ & $19.7(0.8)^{\mathrm{d}}$ & $24.3(2.8)$ & $23.1(3.1)$ & $24.2(2.1)$ \\
Training (hours/week) & $10.6(5.9)$ & $22(5.2)$ & $14.8(5.8)$ & $10.7(5.9)$ & $10.3(4.2)$ \\
LEAF-Q score & $6.4(3.6)$ & $6.3(0.6)$ & $10.6(3.0)^{\mathrm{e}}$ & $5.3(3.2)$ & $5.9(3.5)$ \\
Injury score & $1.4(2.0)$ & $0.7(1.2)$ & $4.8(1.6)^{\mathrm{f}}$ & $1.5(2.1)$ & $1.7(2.0)$ \\
Gastrointestinal function score & $2.6(3.0)$ & $3.7(1.2)$ & $2.5(2.0)$ & $1.8(2.0)$ & $1.5(1.8)$ \\
Menstrual function score & $2.2(1.9)$ & $1.3(0.6)$ & $3(1.8)$ & $1.6(1.5)$ & $2.4(2.4)$ \\
\hline
\end{tabular}

Values are presented as means (standard deviations).

LEAF-Q - Low Energy Availability in Females Questionnaire, BMI - body mass index

${ }^{a}$ Athletes of aesthetic sports were younger than CrossFit, endurance, and combat athletes

b Team sports athletes were younger than CrossFit and endurance athletes

${ }^{\mathrm{c}}$ Athletes of aesthetic sports presented lower body mass than combat athletes

${ }^{\mathrm{d}}$ Athletes of aesthetic sports presented lower BMI than combat and CrossFit athletes

${ }^{\text {e }}$ Combat athletes presented higher LEAF-Q score than CrossFit, endurance, and team sports athletes

${ }^{\mathrm{f}}$ Combat athletes presented higher injury score than all other sports athletes $(p \leq 0.05)$ 
U. De Maria, C. Juzwiak, The risk for the female athlete triad in Brazilian athletes

Table 2. Number of athletes in each sports discipline and group

\begin{tabular}{lll}
\hline Group of athletes* & Characteristic & Sports discipline \\
\hline $\begin{array}{l}\text { G1: weight-sensitive sports } \\
(n=38)\end{array}$ & Endurance sports & $\begin{array}{l}\text { Triathlon }(n=5), \text { medium- and long-distance running }(n=14), \\
\text { cycling }(n=1), \text { swimming }(n=2)\end{array}$ \\
& $\begin{array}{l}\text { Aesthetic sports } \\
\text { Combat sports }\end{array}$ & $\begin{array}{l}\text { Rhythmic gymnastic }(n=3) \\
\text { Muay Thai }(n=1), \text { jiu-jitsu }(n=10), \text { MMA }(n=2)\end{array}$ \\
\hline $\begin{array}{l}\text { G2: team sports } \\
(n=57)\end{array}$ & Team sports & $\begin{array}{l}\text { Soccer and indoor soccer }(n=31), \text { handball }(n=1), \\
\text { volleyball }(n=9), \text { basketball }(n=10), \text { rugby }(n=6)\end{array}$ \\
\hline
\end{tabular}

* 32 CrossFit athletes were not included in this analysis. MMA - mixed martial arts

at the age of 15 years or more. Sixty athletes (47.2\%) answered they noticed menstrual function changes due to modifications in exercise frequency or intensity or an increase in exercise duration.

When the athletes were divided into 2 groups (Table 2): (G1) weight-sensitive sports athletes and (G2) team sports athletes, $50 \%$ of G1 athletes were identified at risk for the triad, while $24.6 \%$ of G2 athletes scored $\geq 8$ at LEAF-Q $(p=0.01)$. In the menstrual function domain, G1 had a higher mean score than G2 (2.4 \pm 1.8 vs. $1.6 \pm 1.5 ; p=0.03$ ), as $26 \%$ of weight-sensitive sports athletes self-reported menstrual irregularities (score $\geq 4$ in the menstrual function domain), while only $9 \%$ of team sports athletes scored $\geq 4$.

\section{Discussion}

This is the first study to use the Brazilian version of LEAF-Q to identify female athletes at risk for the triad from LEA symptoms. It revealed that almost 34\% of 127 Brazilian athletes from 4 different cities and practising several sports disciplines were considered at risk for the triad when assessed by the Brazilian version of LEAF-Q. Studies that applied the original instrument [9] showed the triad risk in $40 \%$ of active Irish females competing in different sports with varied competition levels [17], in 31\% of Swedish cross-country skiing female athletes [18], in 39\% of elite female sprinters from Canada [19], in $62.2 \%$ of English, Swedish, and Danish endurance athletes [9], and in $65 \%$ of Caucasian dancers [20]. In addition, Black et al. [8] identified $63.2 \%$ of physically active females at risk for the triad as assessed by a version of LEAF-Q adapted to New Zealand culture.

This study indicates that the triad risk prevalence is higher when LEA, rather than an eating disorder and/or disordered eating [12, 13], is considered the main component of this syndrome. Energy deficiency may occur owing to an eating disorder and/or disordered eating [21]; however, athletes have many other reasons for failing to adjust the energy intake to exercise energy expenditure, such as loss of appetite due to the high intensity training, adoption of low energy density ultra-healthy diets or restrictive diets in order to optimize body mass or body composition, whether or not to gain competitive advantage [5, 22], lack of financial or time resources [23], and high fibre diet intake, which leads to satiety before providing the needed energy [22].

Melin et al. [9] observed that athletes with LEAF$\mathrm{Q} \geq 8$ tended to have lower body mass and lower body mass index compared with participants classified at a low risk for the triad. However, in this study, there was no association between the LEAF-Q score and selfreported body mass or body mass index; this lack of association may indicate the need for cut-off point reassessment for the Brazilian version of LEAF-Q. Individuals with an energy deficit may become weight stable by the occurrence of compensatory metabolic adaptations, such as a reduction in the resting metabolic rate [24]; thus, body mass is not the most reliable parameter to evaluate the risk for the triad.

Combat athletes had the highest mean LEAF-Q score, mainly because they presented the highest score in the injury domain when compared with other sports disciplines athletes. The high prevalence of risk for the triad among combat athletes in this study was similar to the findings by Torstveit and Sundgot-Borgen [25], who reported more than $70 \%$ of weight-class athletes at risk for the triad. Weight-sensitive sports athletes are considered more susceptible to the risk for the triad as they commonly use one or more pathological methods of weight control [25]. Furthermore, it must be considered that in this contact sport, athletes are subjected to injuries due to the high physical demand of combats, training, and specific techniques to end combat [26], and the high prevalence of injuries cannot be attributed solely to the presence of the triad risk.

Each LEAF-Q domain presents a cut-off point indicating dysfunction [9]; thus, one can use the instru- 
ment to evaluate independent symptoms, as Ackerman et al. [27] did when applying the questionnaire to identify the gastrointestinal status of female athletes. The authors reported a statistically significant association between the gastrointestinal variable and the risk for the triad. In the present study, LEAF-Q $\geq 8$ was significantly associated not only with gastrointestinal dysfunction but also with menstrual dysfunction and the occurrence of injuries in the previous year, when the cut-off points of each domain were analysed separately, as reported by Melin et al. [9] in the original LEAF-Q validation study.

This research also demonstrated an association between the risk for the triad and injury caused by training overload. Other studies have indicated this type of injury in $58.7 \%$ of physically active females [28], $59.1 \%$ of ultra-marathon athletes [29], and $62 \%$ of individual and team sports athletes [17]. Hence, besides being an instrument to identify athletes at risk for the triad, LEAF-Q, both in its original and Brazilian version, seems to be a tool capable of identifying athletes at risk of injury and its potential relationship with LEA [17].

There was a high prevalence of self-reported menstrual dysfunction (46.5\%), such as oligomenorrhea, secondary amenorrhea, and primary amenorrhea, which was also recently identified in dancers (40\%) [20]. Menstrual irregularities are common symptoms of the triad and relative energy deficiency in sport, since LEA is the main cause of functional hypothalamic amenorrhea [3]. This scenario was reported by Fahrenholtz et al. [30], who observed an association between a daily energy deficit of $>300 \mathrm{kcal}$ and athletes' menstrual function changes. In the present study, the prevalence of athletes who scored $\geq 4$ in the LEAF-Q menstrual function domain and consequently presented menstrual function disturbances was similar to that observed in elite sprinter athletes [19]. It is important to monitor these disturbances, as almost half of the participants reported an association between them and an increase in the intensity, frequency, or duration of exercise. The same was observed in $1 / 3$ of Irish physically active females studied by Logue et al. [17]. The menstrual function of female athletes during periods of intense training and/or weight reduction should be observed to avoid oestrogen deficiency and, consequently, bone loss and osteoporosis risk [17].

As observed in this study, Torstveit and SundgotBorgen [25] also demonstrated that a higher percentage of athletes competing in weight-sensitive sports disciplines were identified at risk for the triad compared with athletes practising team sports. Many weight-sen- sitive sports athletes use extremely restrictive methods to lose body mass or maintain a low mass to gain competitive advantage [31]. Serious health issues with sometimes fatal consequences may result from underweight or drastic body mass reduction [2]. Menstrual dysfunction is a well-known consequence of LEA [32]; therefore, weight-sensitive sports athletes turned out more susceptible to the occurrence of menstrual irregularity than team sports athletes [25].

\section{Conclusions}

This is the first report about the risk for the triad in Brazilian female athletes assessed with the Brazilian version of LEAF-Q. In the present study, the triad risk was observed in almost $34 \%$ of Brazilian athletes participating in 14 different sports disciplines. Moreover, the risk for the triad was associated with gastrointestinal and menstrual dysfunctions and injury occurrence, especially with training overload lesions. Weightsensitive sports athletes, mainly combat athletes, were more vulnerable to the risk for the triad when compared with team sports athletes. Given the important prevalence of the triad risk and the physical and physiological consequences of this clinical condition in Brazilian athletes, the results obtained by using the Brazilian LEAF-Q must be objectively examined, since the instrument is a screening tool. Also, concerns should be directed to educating athletes and the coaching staff about LEA and the risk for the triad to avoid health and performance impairments.

\section{Acknowledgments}

The authors are grateful to the Coordenação de Aperfeiçoamento de Pessoal de Nível Superior (CAPES).

\section{Disclosure statement}

No author has any financial interest or received any financial benefit from this research.

\section{Conflict of interest}

The authors state no conflict of interest.

\section{References}

1. De Souza MJ, Nattiv A, Joy E, Misra M, Williams NI, Mallinson RJ, et al. 2014 Female Athlete Triad Coalition consensus statement on treatment and return to play of the female athlete triad: $1^{\text {st }}$ International Conference held in San Francisco, CA, May 2012, and $2^{\text {nd }}$ International Conference held in Indianapolis, IN, May 2013. Clin J Sport Med. 2014;24(2):96-119; doi: 10.1097/JSM.0000000000000085. 
U. De Maria, C. Juzwiak, The risk for the female athlete triad in Brazilian athletes

2. Nattiv A, Loucks AB, Manore MM, Sanborn CF, Sundgot-Borgen J, Warren MP, et al. American College of Sports Medicine position stand. The female athlete triad. Med Sci Sports Exerc. 2007;39(10):1867-1882; doi: 10.1249/mss.0b013e318149f111.

3. Mountjoy M, Sundgot-Borgen J, Burke L, Ackerman KE, Blauwet C, Constantini N, et al. International Olympic Committee (IOC) consensus statement on relative energy deficiency in sport (RED-S): 2018 update. Int J Sport Nutr Exerc Metab. 2018;28(4):316-331; doi: 10.1123/ ijsnem.2018-0136.

4. Gibbs JC, Williams NI, De Souza MJ. Prevalence of individual and combined components of the female athlete triad. Med Sci Sports Exerc. 2013;45(5):985996; doi: 10.1249/MSS.0b013e31827e1bdc.

5. Burke LM, Lundy B, Fahrenholtz IL, Melin AK. Pitfalls of conducting and interpreting estimates of energy availability in free-living athletes. Int J Sport Nutr Exerc Metab. 2018;28(4):350-363; doi: 10.1123/ijsnem.20180142.

6. Mehta J, Thompson B, Kling JM. The female athlete triad: it takes a team. Cleve Clin J Med. 2018;85(4): 313-320; doi: 10.3949/ccjm.85a.16137.

7. Condo D, Lohman R, Kelly M, Carr A. Nutritional intake, sports nutrition knowledge and energy availability in female Australian rules football players. Nutrients. 2019;11(5):971; doi: 10.3390/nu11050971.

8. Black K, Slater J, Brown RC, Cooke R. Low energy availability, plasma lipids, and hormonal profiles of recreational athletes. J Strength Cond Res. 2018;32(10): 2816-2824; doi: 10.1519/JSC.0000000000002540.

9. Melin A, Tornberg ÅB, Skouby S, Faber J, Ritz C, Sjö$\operatorname{din} \mathrm{A}$, et al. The LEAF questionnaire: a screening tool for the identification of female athletes at risk for the female athlete triad. Br J Sports Med. 2014;48(7):540545; doi: 10.1136/bjsports-2013-093240.

10. De Oliveira Coelho GM, Fleiuss de Farias ML, Carvalho de Mendonça LM, de Mello DB, Lanzillotti HS, Ribeiro BG, et al. The prevalence of disordered eating and possible health consequences in adolescent female tennis players from Rio de Janeiro, Brazil. Appetite. 2013;64:39-47; doi: 10.1016/j.appet.2013.01.001.

11. Da Costa NF, Schtscherbyna A, Soares EA, Ribeiro BG. Disordered eating among adolescent female swimmers: dietary, biochemical, and body composition factors. Nutrition. 2013;29(1):172-177; doi: 10.1016/j.nut.2012. 06.007.

12. Parmigiano TR, Monteiro Zucchi EV, de Araujo MP, Cruz Guindalini CS, de Aquino Castro R, de Jármy Di Bella ZIK, et al. Pre-participation gynecological evaluation of female athletes: a new proposal. Einstein. 2014;12(4):459-466; doi: 10.1590/S1679-45082014AO 3205.

13. Schtscherbyna A, Soares EA, de Oliveira FP, Ribeiro BG. Female athlete triad in elite swimmers of the city of Rio de Janeiro, Brazil. Nutrition. 2009;25(6):634-639; doi: 10.1016/j.nut.2008.11.029.
14. De Maria UP. Transcultural adaptation and validation of the Low Energy Availability in Females Questionnaire (LEAF-Q) [in Portuguese]. (Unpublished master's thesis). Santos: Federal University of Sao Paulo; 2019.

15. Guillemin F, Bombardier C, Beaton D. Cross-cultural adaptation of health-related quality of life measures: literature review and proposed guidelines. J Clin Epidemiol. 1993;46(12):1417-1432; doi: 10.1016/08954356(93)90142-n.

16. Beaton DE, Bombardier C, Guillemin F, Ferraz MB. Guidelines for the process of cross-cultural adaptation of self-report measures. Spine. 2000;25(24):3186-3191; doi: 10.1097/00007632-200012150-00014.

17. Logue DM, Madigan SM, Heinen M, McDonnell S-J, Delahunt E, Corish CA. Screening for risk of low energy availability in athletic and recreationally active females in Ireland. Eur J Sport Sci. 2019;19(1):112122; doi: 10.1080/17461391.2018.1526973.

18. Carr A, McGawley K, Govus A, Andersson EP, Shannon OM, Mattsson S, et al. Nutritional intake in elite cross-country skiers during two days of training and competition. Int J Sport Nutr Exerc Metab. 2019;29(3): 273-281; doi: 10.1123/ijsnem.2017-0411.

19. Sygo J, Coates AM, Sesbreno E, Mountjoy ML, Burr JF. Prevalence of indicators of low energy availability in elite female sprinters. Int J Sport Nutr Exerc Metab. 2018;28(5):490-496; doi: 10.1123/ijsnem.2017-0397.

20. Civil R, Lamb A, Loosmore D, Ross L, Livingstone K, Strachan F, et al. Assessment of dietary intake, energy status, and factors associated with RED-S in vocational female ballet students. Front Nutr. 2019;5:136; doi: 10.3389/fnut.2018.00136.

21. Melin AK, Heikura IA, Tenforde A, Mountjoy M. Energy availability in athletics: health, performance, and physique. Int J Sport Nutr Exerc Metab. 2019;29(2):152164; doi: 10.1123/ijsnem.2018-0201.

22. Melin A, Tornberg ÅB, Skouby S, Møller SS, Faber J, Sundgot-Borgen J, et al. Low-energy density and high fiber intake are dietary concerns in female endurance athletes. Scand J Med Sci Sports. 2016;26(9):10601071; doi: 10.1111/sms.12516.

23. Burke LM, Close GL, Lundy B, Mooses M, Morton JP, Tenforde AS. Relative energy deficiency in sport in male athletes: a commentary on its presentation among selected groups of male athletes. Int J Sport Nutr Exerc Metab. 2018;28(4):364-374; doi: 10.1123/ijsnem.20180182.

24. Loucks AB, Kiens B, Wright HH. Energy availability in athletes. J Sports Sci. 2011;29(Suppl. 1):S7-S15; doi: 10.1080/02640414.2011.588958.

25. Torstveit MK, Sundgot-Borgen J. The female athlete triad: are elite athletes at increased risk? Med Sci Sports Exerc. 2005;37(2):184-193; doi: 10.1249/01.mss.0000 152677.60545.3a.

26. Machado AP, Machado GP, De Marchi T. The prevalence of injuries in jiu-jitsu according to the report of the athletes participating in 2006 world championships 
[in Portuguese]. ConScientiae Saúde. 2012;11(1):85-93; doi: 10.5585/conssaude.v11n1.3033.

27. Ackerman KE, Holtzman B, Cooper KM, Flynn EF, Bruinvels G, Tenforde AS, et al. Low energy availability surrogates correlate with health and performance consequences of Relative Energy Deficiency in Sport. Br J Sports Med. 2019;53(10):628-633; doi: 10.1136/ bjsports-2017-098958.

28. Slater J, McLay-Cooke R, Brown R, Black K. Female recreational exercisers at risk for low energy availability. Int J Sport Nutr Exerc Metab. 2016;26(5):421427; doi: 10.1123/ijsnem.2015-0245.

29. Folscher L-L, Grant CC, Fletcher L, Janse van Rensberg DC. Ultra-marathon athletes at risk for the female athlete triad. Sports Med Open. 2015;1(1):29; doi: 10.1186/s40798-015-0027-7.

30. Fahrenholtz IL, Sjödin A, Benardot D, Tornberg ÅB, Skouby S, Faber J, et al. Within-day energy deficiency and reproductive function in female endurance athletes. Scand J Med Sci Sports. 2018;28(3):1139-1146; doi: 10.1111/sms.13030.

31. Ackland TR, Lohman TG, Sundgot-Borgen J, Maughan RJ, Meyer NL, Stewart AD, et al. Current status of body composition assessment in sport: review and position statement on behalf of the ad hoc research working group on body composition health and performance, under the auspices of the I.O.C. Medical Commission. SportsMed.2012;42(3):227-249; doi:10.2165/11597140 $-000000000-00000$.

32. Loucks AB, Thuma JR. Luteinizing hormone pulsatility is disrupted at a threshold of energy availability in regularly menstruating women. J Clin Endocrinol Metab. 2003;88(1):297-311; doi: 10.1210/jc.2002-020369. 